\title{
SSC 50mm Dipole Magnet Cryostat Thermal Measurement Results
}

\author{
W.N. Boroski, T.H. Nicol, M.K. Ruschman and C.J. Schoo \\ Fermi National Accelerator Laboratory \\ P.O. Box 500, Batavia, Illinois 60510
}

May 1993

Presented at the Fifth International Industrial Symposium on the Super Collider (IISSC), San Francisco, CA., May 6-8, 1993 


\section{Disclaimer}

This report was prepared as an account of work sponsored by an agency of the United States Government. Neither the United States Government nor any agency thereof, nor any of their employees, makes any warranty, express or implied, or assumes any legal liability or responsibility for the accuracy, completeness, or usefulness of any information, apparatus, product, or process disclosed, or represents that its use would not infringe privately owned rights. Reference herein to any specific commercial product, process, or service by trade name, trademark, manufacturer, or otherwise, does not necessarily constitute or imply its endorsement, recommendation, or favoring by the United States Government or any agency thereof. The views and opinions of authors expressed herein do not necessarily state or reflect those of the United States Government or any agency thereof. 
SSC 50mm DIPOLE MAGNET CRYOSTAT THERMAL MEASUREMENT RESULTS

\author{
W.N. Boroski, T.H. Nicol, M.K. Ruschman, and C.J. Schoo \\ Fermi National Accelerator Laboratory \\ P.O. Box 500 \\ Batavia, IL 60510 USA
}

\title{
INTRODUCTION
}

A prototype Superconducting Super Collider (SSC) $50 \mathrm{~mm}$ dipole magnet cryostat ${ }^{1}$, DCA323, was instrumented at Fermilab and delivered to the SSC Laboratory for installation into the accelerator systems string test facility. In series with other magnets, the instrumented cryostat will be used to quantify and verify cryostat thermal performance with respect to design requirements. Prior to leaving Fermilab, DCA323 was subjected to magnetic testing at the Magnet Test Facility (MTF). This presented an opportunity to obtain preliminary thermal performance data under simulated operating conditions. It should be noted that measurements of overall cryostat thermal performance were not possible during the MTF measurements as the magnet test stands are designed for magnetic rather than thermal testing. They are not designed to limit heat inleak to the ends of the cryostat, which has been shown to have a significant effect on overall measured thermal performance ${ }^{2}$. Nonetheless, these measurements do offer insight into the performance of several of the cryostat components and sub-systems.

\section{CRYOSTAT INSTRUMENTATION}

DCA323 was instrumented with 127 transducers of various type to measure temperature, strain, and vacuum. Thermometers were installed on the inner and outer thermal shields, on one support post assembly, internal to the inner and outer $80 \mathrm{~K}$ MLI blankets, and on the cryostat vacuum shell. Strain gages were installed on each support post to measure axial loads applied during thermal cycling. Vacuum gauges were installed in the vacuum shell to measure system pressure. A comprehensive discussion of the instrumentation is not possible here given space constraints. However, information on exact transducer placement, transducer types, etc., is detailed in an internal Fermilab document ${ }^{3}$.

\section{DATA ACQUISITION SYSTEM}

A PC-based data acquisition system monitored transducer outputs on a continuous basis, logging readings to file on 30-minute intervals. The stand-alone data acquisition system consisted of an IBMcompatible computer connected to a data acquisition (DA) unit via an IEEE-488 interface. All transducer outputs were connected to the DA unit. Constant current sources provide excitation for the transducers: separate current sources were used for each transducer type. Current polarity was reversed and averaged for each measurement to eliminate thermal EMF effects. 


\section{THERMAL PERFORMANCE RESULTS}

\section{Thermal Cycling}

DCA323 was subjected to two thermal cycles during testing at MTF. A thermal cycle is defined as a cooldown to operating temperature and subsequent warm-up to ambient temperature. Of particular interest is the length of time required for the MLI blankets to equilibrate during transient conditions. Figure 1 shows the change in temperature of an inner layer of the 80K MLI blanket stack from the start of cooldown \#1. Layer 32 was selected as it is near the middle of the 64-layer blanket stack. Note that even after 170 hours, the temperature of the layer is changing, albeit at a very slow rate $\approx 70 \mathrm{mK}$ per hour). For these measurements, the $80 \mathrm{~K}$ MLI system began approaching equilibrium after approximately 170 hours, or 150 hours after the $80 \mathrm{~K}$ shield reached operating temperature. Thermally, the second thermal cycle occurred much like the first. Based upon the results of the two thermal cycles, the conclusion is that the $80 \mathrm{~K}$ blanket assembly equilibrates approximately 7 days after the $80 \mathrm{~K}$ shield reaches steady-state operating temperature.

\section{Temperature Change in MLI Blanket Layer 32}

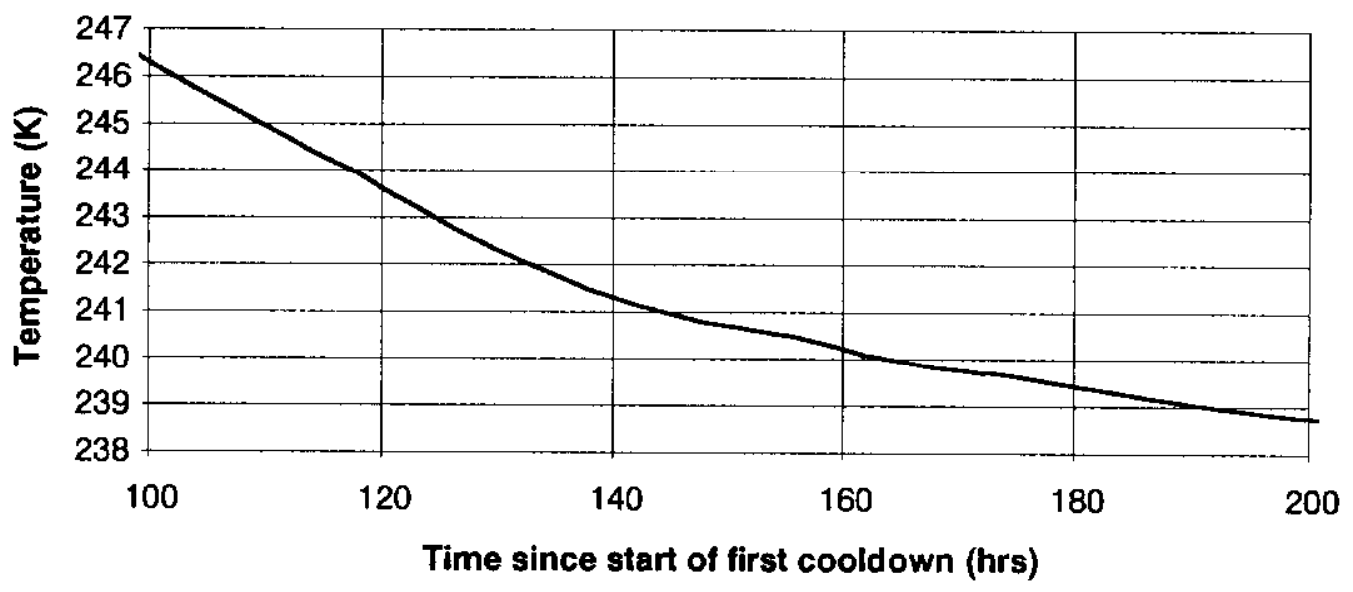

Figure 1. Time required for MLI blanket to reach equilibrium during initial cooldown.

\section{Support Post Performance}

The support post located between the center and end posts on the lead end of the magnet was instrumented with thermometers and strain gages positioned along the conductive path. Steady-state support post temperature profiles derived from data recorded on three separate days are presented in Table 1. The values in the table were obtained by averaging data recorded over 10 -hour periods.

By design, the top of the support post should operate near $4.2 \mathrm{~K}$. However, in operation the post top equilibrates at a higher temperature due to thermal resistance of the cold mass cradle assembly. These measurements indicate a $2.25 \mathrm{~K}$ temperature gradient across the cradle connection. The table also shows that the $80 \mathrm{~K}$ intercept operated at a temperature significantly above the design temperature of $80 \mathrm{~K}$. This is due in part to the MTF liquid nitrogen supply system which caused the $80 \mathrm{~K}$ thermal shield to operate near $90 \mathrm{~K}$. Notwithstanding, there was a significant thermal gradient between the thermal shield and support post intercept which may suggest some inefficiency in the thermal shorting straps. 
Table 1. Steady-state support post temperature profile.

\begin{tabular}{|l|c|c|c|}
\cline { 2 - 4 } \multicolumn{1}{c|}{} & \multicolumn{3}{c|}{$\begin{array}{c}\text { Temperature (K) } \\
\text { Data recorded on: }\end{array}$} \\
\hline \hline \multicolumn{1}{c|}{ Post Location } & $\mathbf{1 0 / 2 4 / 9 2}$ & $\mathbf{1 1 / 0 2 / 9 2}$ & $\mathbf{1 1 / 1 0 / 9 2}$ \\
\hline 4K ring & 6.323 & 6.234 & 6.781 \\
\hline GRP tube, near 4K ring & 13.037 & 13.100 & 13.315 \\
\hline GRP tube, near 20K intercept & 16.696 & 16.815 & 16.885 \\
\hline 20K intercept & 18.391 & 18.623 & 18.449 \\
\hline 80K intercept & 103.798 & 103.715 & 105.294 \\
\hline FRP tube, near 80K intercept & 185.570 & 184.822 & 186.165 \\
\hline FRP tube, near 300K ring & 234.118 & 233.065 & 234.520 \\
\hline 300K ring & 290.606 & 289.224 & 290.707 \\
\hline \multicolumn{3}{|c|}{} \\
\hline \hline Heat load into 4K ring & $0.041 \mathrm{~W}$ & $0.042 \mathrm{~W}$ & $0.040 \mathrm{~W}$ \\
\hline Heat load into 80K intercept & $3.250 \mathrm{~W}$ & $3.220 \mathrm{~W}$ & $3.234 \mathrm{~W}$ \\
\hline
\end{tabular}

Heat load into the $4 \mathrm{~K}$ ring and the $80 \mathrm{~K}$ intercept were calculated using physical properties and measured temperatures and are included in Table 1. The average calculated heat load into $4 \mathrm{~K}$ was 0.041 watts, which is greater than the design heat load of 0.032 watts. This calculation is made using available thermal conductivity values for a graphite reinforced plastic that may be of slightly different composition than the composite tube actually used. Thermal conductivity of the actual material has not been characterized. The average calculated heat load into the $80 \mathrm{~K}$ intercept is 3.235 watts, slightly greater than the design heat load of 3.160 watts. One would have expected the calculated heat load into the $80 \mathrm{~K}$ intercept to be slightly lower than design given the higher operating temperature of the intercept. As it was not possible to install instrumentation on the lower end of the support post inner tube, it is not possible to calculate the conductive heat load into the $20 \mathrm{~K}$ intercept.

\section{Blanket Performance}

There were a total of 54 thermometers in the $80 \mathrm{~K}$ MLI blankets. Arrays of 18 thermometers each were located at three positions along the cryostat length. Figure 2 shows the temperature profile through the inner and outer blankets at one location during one steady-state period. Temperatures plotted in the graph were averaged over a 24 -hour period. Similar graphs were made using data from thermometers located at the other two thermal "slices" through the blanket; those temperature profiles were nearly identical to that shown in Figure 2.

Analysis of the thermometer locations showed that the temperature measurements were significantly influenced by the sewn seams on the adjacent blanket. When the blankets are installed in the cryostat, the blanket seam/joint areas are offset to preclude excessive build-up due to hook-and-loop closures, additional cover materials, etc. Unfortunately, this offset caused the thermometers in the instrumented blankets to be located immediately above or below the seam/joint area of the adjacent blanket, which caused the step in the thermal profile. The result of this thermometer positioning is that data obtained from these instrumented MLI blankets is of little use in predicting heat flux through the MLI, or for thermal modeling purposes. Nonetheless, the data clearly shows that the seams have a significant impact on the thermal gradient through the adjacent blanket, which equates to a potentially significant impact on overall thermal performance. It is not clear from this data how localized an effect this is. 


\section{Temperature Profile through $80 \mathrm{~K}$ MLI Blankets}

\section{(Segment 2)}

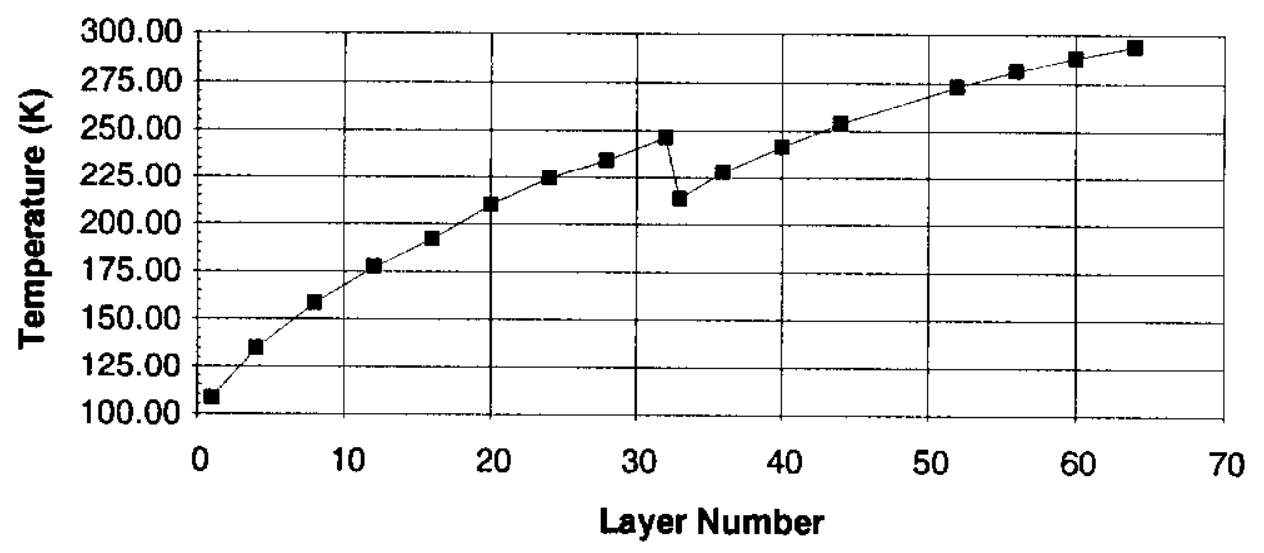

Figure 2. Temperature profile through the $80 \mathrm{~K}$ MLI blankets.

Data consistently showed that the temperature gradients through the blanket at the three instrumented "slices" were nearly identical. One of the concerns with long cylindrical applications of MLI is the ability to evacuate the interstitial regions of the multilayer assembly. MLI measurements have recorded the temperature profile through an $80 \mathrm{~K}$ blanket under various insulating vacuum levels ${ }^{4}$. A distinct curve in the temperature profile was observed at pressures near $10^{-5}$ torr; however, as the pressure increased above $10^{-4}$ torr the curve became linear due to increased residual gas conduction. Figure 2 shows the curve to be non-linear, suggesting that the interstitial volumes had been adequately evacuated to reduce residual gas conduction effects. And the fact that the profile was the same at several positions along the blanket length suggests that the blanket had been uniformly evacuated over its length.

\section{Conclusions}

Measurements made on DCA323 indicate the cryostat instrumentation is functioning properly. Placement of the MLI blanket thermometers caused the data to be of limited use in calculating heat flux through the blanket assembly. However, the thermometers did indicate that the interstitial volume of the blankets was evacuated to sufficiently low levels to preclude excessive heat transfer through residual gas conduction. Calculations of conductive heat transfer through the instrumented support post indicate that heat loads into the $4 \mathrm{~K}$ and $80 \mathrm{~K}$ temperature stations may exceed the design budget by a small amount.

\section{REFERENCES}

1. Nicol, T.H., "SSC 50mm Collider Dipole Cryostat Design", in: "Advances in Cryogenic Engineering", Vol 37A, Plenum Press, New York (1991).

2. Niemann, R.C., et al., "SSC Dipole Magnet Cryostat Thermal Model", in: "Advances in Cryogenic Engineering", Vol. 33, Plenum Press, New York (1988).

3. Boroski, W.N., "Instrumentation of SSC Dipole Cryostat DCA323", Fermilab TSS/Engineering Laboratory Document IGEL-040.

4. Gonczy, J.D., Boroski, W.N., and Niemann, R.C., "Thermal performance measurements of a 100 percent polyester MLI system for the Superconducting Super Collider", in: Advances in Cryogenic Engineering, Vol. 35, Plenum Press, New York (1989). 